\title{
Homogenization of the interfacial bonding of compound-cast AA7075/6060 bilayer billets by co-extrusion
}

\author{
Hui Chen ${ }^{1}$ (D) Danai Giannopoulou ${ }^{2} \cdot$ Thomas Greß $^{3} \cdot$ Jonas Isakovic $^{2} \cdot$ Tim Mittler $^{3} \cdot$ Wolfram Volk $^{3}$. \\ Noomane Ben Khalifa ${ }^{1,2}$
}

Received: 10 September 2020 / Accepted: 6 May 2021 / Published online: 16 May 2021

(C) The Author(s) 2021

\begin{abstract}
A process chain of compound casting and co-extrusion of AA7075/6060 bilayer billets is introduced to manufacture hybrid components with strength in the core and good corrosion-resistance in the shell. Using optimized compound casting parameter, metallurgical bonding between the shell AA6060 and the core AA7075 can be achieved through remelting and recrystallization of the substrate AA7075. The locally unequal thermal conditions at the interface induces partially weak bonding. The bonding strength in greater distance from the casting gate is generally lower. Hot extrusion is applied to improve the interfacial bonding. Comparisons of the microstructure and the shear strength between as-cast billet and extrudate present the homogenization of the interfacial bonding through the process chain.
\end{abstract}

Keywords compound casting $\cdot$ co-extrusion $\cdot$ bond strength

\section{Introduction}

In recent years, there is an increasing trend towards the development of hybrid structural components. The advantage of such load-adapted components lies in particular in the combination of advantageous mechanical, physical or chemical properties of various materials in one component. The potential application of hybrid structure component are stringer profiles in the fuselage of airplanes or profiles in chassis of trains and cars which use high strength, lightweight material without compromising of corrosion resistance. An example of hybrid steering tie rod composites of AA7075 core and AA6060 shell was demonstrated in [1].

One possibility for the production of hybrid components is the co-extrusion of billets made of different materials. The

Hui Chen

hui.chen@leuphana.de

1 Institute of Product and Process Innovation, Leuphana University of Lüneburg, Universitätsallee 1, 21335 Lüneburg, Germany

2 Institute of Material and Process Design, Helmholtz-Zentrum Hereon, Max- Planck-Straße 1, 21052 Geesthacht, Germany

3 Chair of Metal Forming and Casting, Technical University of Munich, Walther-Meißner-Straße 4, 85748 Garching, Germany billets used consist of a core and a sleeve material, which are manufactured independently of each other and are interlocked for extrusion [2]. Scientific investigations show, that the realization of a sufficiently composite quality represents a particular challenge for the compound cold extrusion process. In investigations by [3], although cold-welded bimetals could be manufactured from the material combinations titanium/ aluminum and titanium/austenitic steel. This was only possible by the preparation of the joints with special coatings. Research by [4] showed, that the tensile strengths of the joints behave in proportion to the surface enlargement. Cold welding is understood to be the formation of adhesive bonds that occur when metals come into contact, when the oxide layers are torn open under high surface pressure and magnification [5]. In [6], the influence of various factors on the quality of cold welding is discussed. Therein, the avoidance of fats and the presence of oxide-layer-free surfaces are mentioned as a prerequisite. An important aspect is the enlargement of the surfaces in order to break up the oxide layers. In this case, the required surface enlargement becomes lower with increasing temperature.

With regard to the temperature, [7] investigated the coextrusion of the lightweight materials aluminum and magnesium in the indirect hot extrusion process at different temperatures $\left(380^{\circ} \mathrm{C}-420^{\circ} \mathrm{C}\right)$ and die angles. EN AW-6060 in various wall thicknesses was chosen as sleeve material of the billets. The core consisted of AZ31 magnesium, which was 
Table 1 Chemical composition of aluminum alloys according to [16]

\begin{tabular}{llllllll}
\hline Cast alloy & $\begin{array}{l}\mathrm{Al} \\
\text { in } \%\end{array}$ & $\begin{array}{l}\mathrm{Cu} \\
\text { in } \%\end{array}$ & $\begin{array}{l}\mathrm{Si} \\
\text { in } \%\end{array}$ & $\begin{array}{l}\mathrm{Fe} \\
\text { in } \%\end{array}$ & $\begin{array}{l}\mathrm{Mg} \\
\text { in } \%\end{array}$ & $\begin{array}{l}\mathrm{Zn} \\
\text { in } \%\end{array}$ & $\begin{array}{l}\mathrm{Cr} \\
\text { in } \%\end{array}$ \\
\hline AA7075 & 90.05 & 1.63 & 0.18 & 0.27 & 2.20 & 5.48 & 0.19 \\
AA6060 & 98.80 & 0.02 & 0.50 & 0.17 & 0.48 & 0.01 & 0.02 \\
\hline
\end{tabular}

separated from the sleeve material by a single or double layer of zinc or titanium foil in some experiments. The tests show, that under the given conditions it is not possible to achieve sufficient bond strength without an intermediate film. In addition, it should be noted that higher temperatures and extrusion ratios as well as thicker aluminum sleeves increase the bonding strength for the co-extrusion of aluminum and magnesium materials.

The extrusion billets that prepared by interlock initially has no bonding. In the work of [8], two different types of block preparations are investigated. In variant 1 , the titanium core is cast around with molten aluminum. In variant 2 , the production was carried out by inserting the titanium core into a drilled aluminum bolt. The tests carried out by direct extrusion show that, despite the occurrence of core fractures, it is fundamentally possible to produce aluminum-titanium composite profiles. Irrespective of the type of block preparation, these profiles have integral bonds with intermetallic phases within the boundary layer. Deeper microstructural analyzes of the boundary layer were performed by [9]. By mechanical testing of tensile specimens taken from the profiles, differences regarding the tensile strength as a function of the block preparation could be detected. Samples extracted from the cast block (variant 1) reached a tensile strength of about $40 \mathrm{MPa}$. The breakage of the sample took place in the aluminum. The composite zone remained undamaged. In contrast, samples, in which the titanium core was inserted, the aluminum block (variant 2) had significantly lower strengths.

Fig. 1 Setup for discontinuous compound casting of aluminum billets: (a) substrate casting, (b) compound casting according to [16]
Production of composite billets by casting technique allows the formation of a cohesive metallic bond. Different mechanisms are responsible for the formation of bonds at the interface between the participating composite partners. In particular, melting, crystallization and diffusion processes as well as dissolution and precipitation processes with the formation of mixed crystals and/or intermetallic phases are of importance [10]. Fundamental experimental and numerical investigations on the boundary layer formation and characterization of compound casting of different aluminum alloys on a laboratory scale are described in [11].

Regarding the technological implementation of compound casting, some discontinuous and continuous processes for the production of multi-component castings have been developed in the past. In discontinuous compound casting procedures, which are described in detail for example in [12-14], a fundamental distinction is made as to whether the composite casting is formed by casting various melts into a mold or by pouring a melt onto a solid in the mold cavity. An example of a continuous composite casting process is the technology known as Novelis Fusion ${ }^{\mathrm{TM}}$, which is used industrially for the production of composite cast ingots made of different aluminum alloys [15].

For the assessment of the interfacial bonding in material composites produced by compound casting as well as co-extrusion, various methods of material testing are used to allow a qualitative or quantitative characterization of the structure and the mechanical properties. To determine the mechanical properties of composites, it is useful to measure the microhardness to record the effects of diffusion processes and microstructural transformations at the interface [11]. In addition, there are several destructive testing methods to determine the bond strength, which is often considered as a relevant parameter for assessing the composite quality.

Metallurgical bonding was achieved by means of compound casting of the equal alloy systems AA7075/6060 [16]. The formation of solid solutions at the interface provides (a)

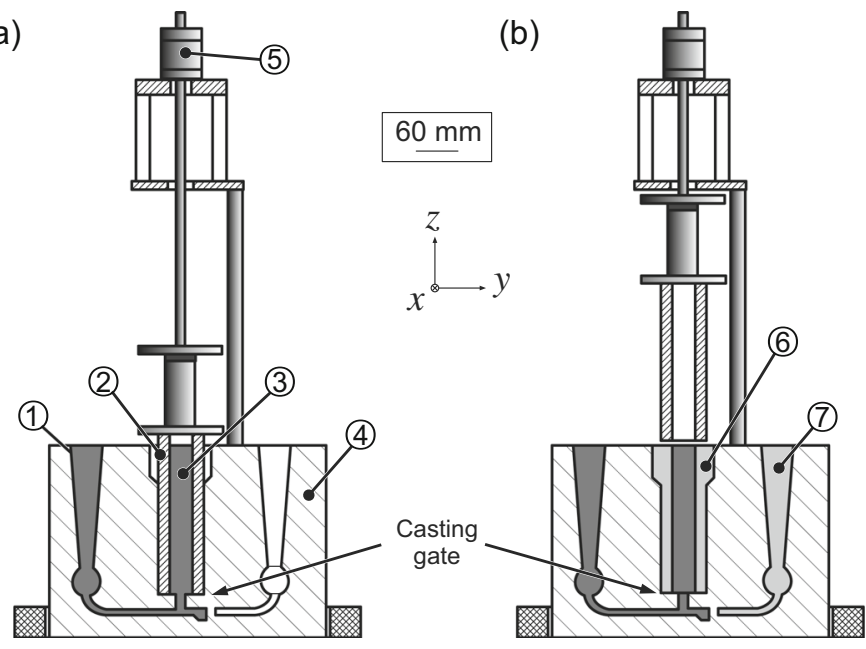

(1) Core melt supply

(2) Graphite insert

(3) Core (AA7075)

(4) Sand mold

(5) Withdrawing device

(6) Sleeve (AA6060)

(7) Sleeve melt supply 
Fig. 2 Compound-cast billets: (a) extracted specimen for metallography and push-out test; (b) extracted specimen for producing extrusion billet (a)

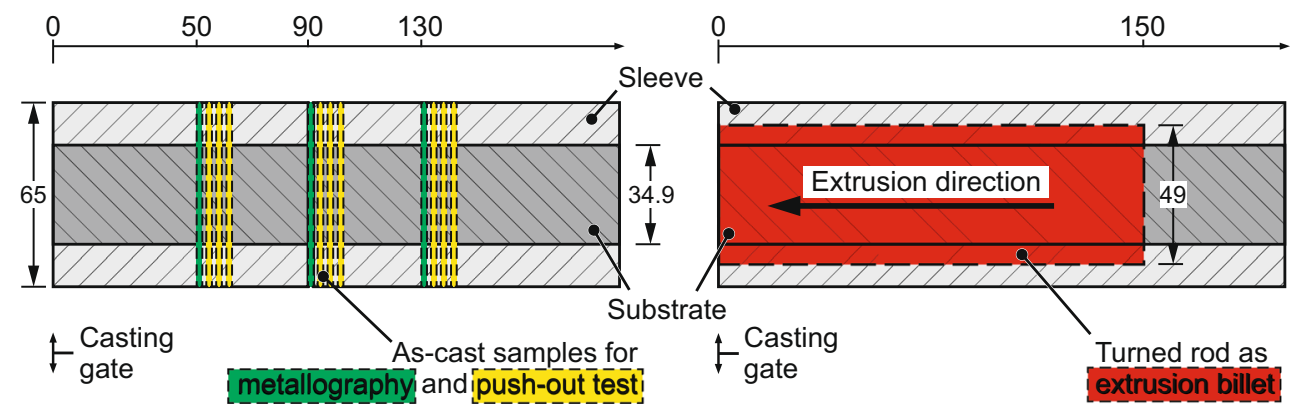

a high potential in terms of bonding strength and load-bearing capacity. Graded material properties are confined to a small transition zone between the layers [17]. Brittle intermetallic layers could not be determined. Nevertheless, in static compound casting, the unequal thermal conditions over the height of the cast product induce the weakening of the bonding in greater distance from the casting gate.

In this article, a hot extrusion process following the compound casting was conducted to homogenize the interfacial bonding throughout the as-cast billets. The evolution of interfacial bonding during the process chain of compound casting and co-extrusion of AA7075/6060 bilayer billets are studied. The boundary layer properties are evaluated by metallography, chemical composition analysis as well as mechanical testing.

\section{Experimental conditions}

\section{Materials}

7075 aluminum alloy (AA7075) is a high strength material used for stressed structure parts in transport applications, including marine, automotive and aviation, e.g. aircraft fittings, gears and shafts. The 7075 aluminum alloy has lower resistance to corrosion than 6060 aluminum alloy (AA6060), while the AA6060 has also good weldability plus sufficient cold formability. In this work, the 7075 and 6060 aluminum alloys are used as the core and sleeve material respectively in fabricating a rotationally symmetric hybrid part, which has high strength and excellent corrosion resistant properties at the surface and a ductile alloy in the bulk. The chemical compositions of the 7075 and 6060 aluminum alloy are given in Table 1.

\section{Static compound casting}

Hybrid aluminum billets (core/substrate: AA7075; shell: AA6060) were formed by means of static gravity sand mold casting (Fig.1). The gravity casting mold system was designed as a printed furan resin sand mold. The applied cast alloys were molten in two separate resistance-heated furnaces and manually carried to the test setup. The 7075 core alloy - the so-called substrate - was poured into the melt supply. A cylindrical graphite insert, which was placed inside the printed sand mold and attached to an electrical withdrawing device, formed the cavity of the substrate cast body. Reaching a specific substrate temperature, the compound casting process was initiated by drawing the graphite insert with a constant speed of $24 \mathrm{~mm} / \mathrm{s}$ in z-direction and pouring the 6060 shell alloy. The shell material filled the running system and the rotationally symmetric shell cavity. The as-cast compound cylinder had a height of approximately $200 \mathrm{~mm}$ and a diameter of $65 \mathrm{~mm}$. The interface diameter was approximately 34.9 $\mathrm{mm}$. A detailed description of the casting procedure and thermal conditions is given in[16].

To investigate the interface character between core and sleeve materials, cross-sectional samples were extracted from the as-cast aluminum bimetals. The extraction location from as-cast disk-shaped samples are 50, 90 and $130 \mathrm{~mm}$ above the casting gate. Those specimens were indicated as cross-
Fig. 3 Dimensions of the extrusion billet and tools

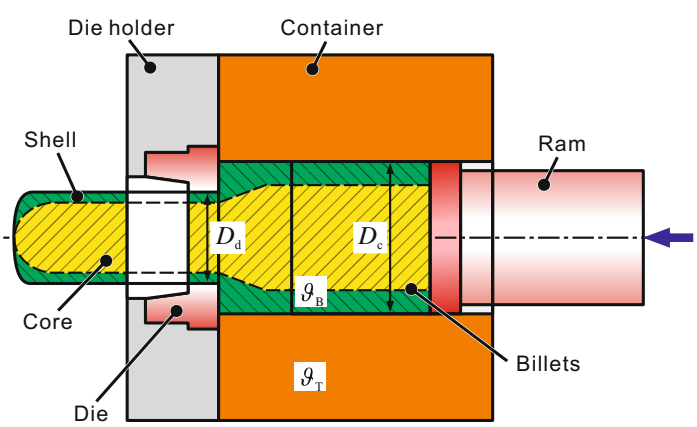

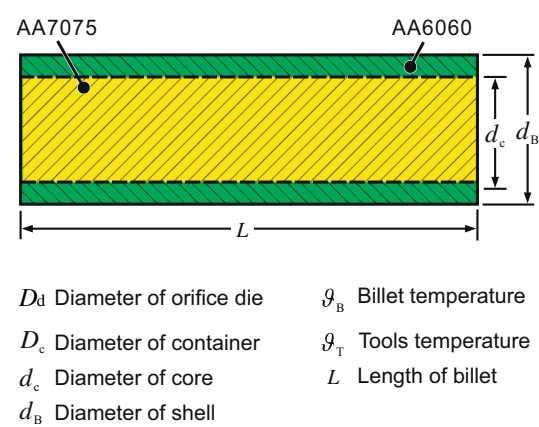


Fig. 4 Cross-sectional samples from extrudate billet

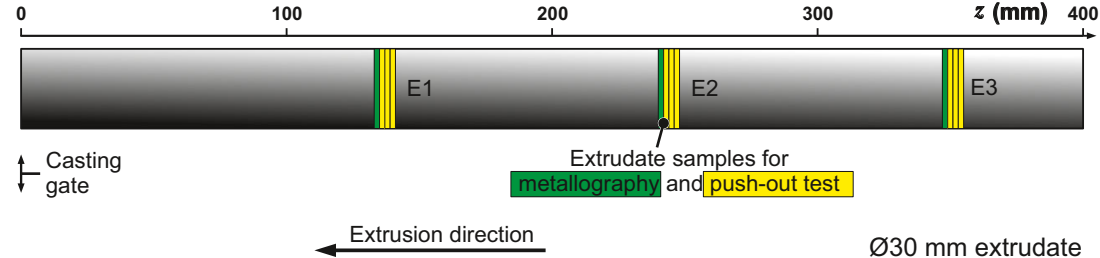

sectional sample C1, C2 and C3 respectively (Fig. 2(a)). The aluminum compound specimens were etched using sodium hydroxide and potassium permanganate. The material structure and phase composition near the interface was investigated using SEM-EDS. Additional three specimens were used for push-out testing to evaluate the axial shear strength of the bonding. The hardness of the near-interface region of the compound specimens was analyzed by micro-indentation testing according to [16].

\section{Hot extrusion}

Additional compound-cast billet, which was produced under the same casting condition as the previous one that was optically and mechanically analyzed, was hot extruded on the machine of Müller Engineering with maximum load of 2.5 MN. The press container had a diameter of $D_{C}=50 \mathrm{~mm}$. Higher extrusion ratio is expected to generate better bonding strength in favorable of higher hydrostatic pressure. Nevertheless, the extrusion die selected for the experiments was a flat-face die with a diameter of $D_{d}=30 \mathrm{~mm}$ resulting in the extrusion ratio $R=2.8$, which is suitable for further processing (i.e. hot forging into composite steering tie rod) as demonstrated in [1]. Billet from the compound casting was firstly machined to an outer diameter of $D_{B}=49 \mathrm{~mm}$ and lengths of $L=150 \mathrm{~mm}$ measured from the casting gate (Fig. 3(b)). The billet was heated in the furnace to $\vartheta_{B}=$ $480^{\circ} \mathrm{C}$ and the dwell time was $3 \mathrm{~h}$ for homogenization. The container and the die was also heated to $\vartheta_{T}=480^{\circ} \mathrm{C}$. The speed of the ram was $2 \mathrm{~mm} / \mathrm{s}$ and kept constant during the extrusion process. The extrudate was cooled down to room temperature in the air.

The length of the extrudate after extrusion was $400 \mathrm{~mm}$. Cross-sectional samples were extracted from the extrudate, corresponding to the specimen location from as-cast billets, for metallography and mechanical testing (Fig. 4. For the metallographic characterization, each specimen was mounted in resin, ground (SiC papers: 300, 500, 800, 1000, 1200, 2500) and polished in two steps (first step with a $3 \mu \mathrm{m}$ diamond paste and red lubricant and second step with an OPS solution). The microstructures for light optical microscopy (LOM) were etched with Barker reagent using an electro-chemical polishing machine for $120 \mathrm{~s}$ (Struers GmbH, Willich, Germany, LectroPol-5). They were indicated as cross-sectional samples E1, E2 and E3. Energy-dispersive X-ray spectroscopy analysis (EDS) using a Tescan Vega3 scanning electron microscope (SEM) (Brno, Chech Republic) was performed for the investigation of the near-interface material structure and phase composition. The specimens for the scanning electron microscopy investigation were not etched but washed immediately before the measurements with ethanol and water. Vickers micro hardness test HV0.1 was performed with an EMCO test machine using an indentation load of $0.1 \mathrm{~kg}$ and was conducted accordingly to the as-cast specimens.

\section{Push-out test}

Push-out testing of both as-cast specimens and extrudate specimens were under comparable conditions. The push-out test setup and configuration for as-cast specimens refer to [16]. The setup of the push-out test for the extrudate specimens is illustrated in
Fig. 5 Push-out test setup for extrudate specimen

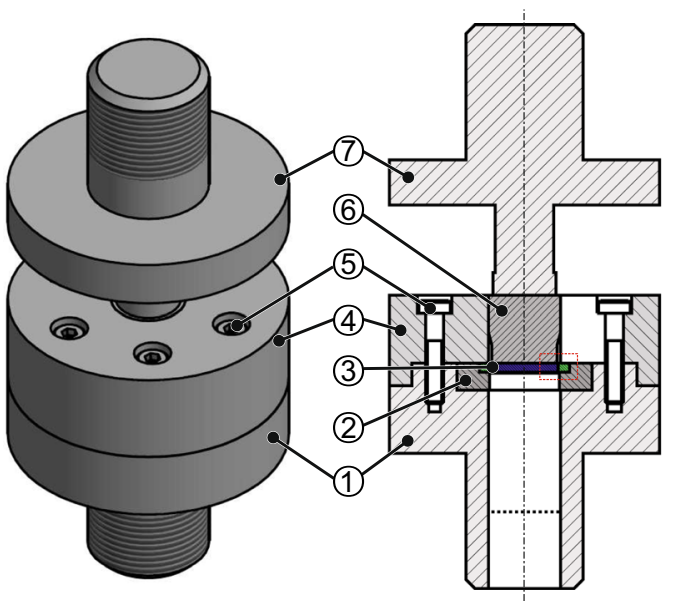

(1) Die holder

(2) Die

(5) Bolt

(3) Sample

(6) Punch

(4) Sleeve holder

(7) Ram

$d_{\mathrm{p}}$ Punch diameter

$d_{\mathrm{i}}$ Interface diameter

$d_{\mathrm{d}}$ Die diameter

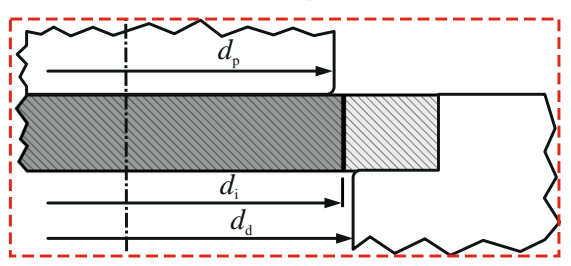


Table 2 Dimensions of the pushout test

\begin{tabular}{lll}
\hline & As-cast specimen $(\mathrm{C} 1, \mathrm{C} 2, \mathrm{C} 3)$ & Extrudate specimen (E1, E2, E3) \\
\hline Interface diameter $\boldsymbol{d}_{\boldsymbol{i}}$ in [mm] & $34.9 \pm 0.10$ & $\boldsymbol{d}_{\boldsymbol{i}}$ \\
Punch diameter $\boldsymbol{d}_{\boldsymbol{p}}$ in [mm] & $34.0 \mathrm{j} 6$ & $\boldsymbol{d}_{\boldsymbol{i}}-0.9$ \\
Die diameter $\boldsymbol{d}_{\boldsymbol{d}}$ in [mm] & $35.0+0.01$ & $\boldsymbol{d}_{\boldsymbol{i}}+0.1$ \\
Specimen thickness $\boldsymbol{t}$ in [mm] & $2.0 \pm 0.1$ & $2.0 \pm 0.1$ \\
Punch/die edge radius $\boldsymbol{r}_{\boldsymbol{p} / \boldsymbol{d}}$ in [mm] & 0.1 & 0.1 \\
Die clearance $\boldsymbol{c}$ in [mm] & 0.5 & 0.5 \\
\hline
\end{tabular}

Fig. 5, which was conducted using the Zwick Z250 testing machine from Zwick/Roell AG, Ulm, Germany. Both tests were performed at room temperature. The punch and die were made of high-speed steel. The sleeve holder was fixed to the die holder by six screws (torque $7 \mathrm{Nm}$ per screw). The punch displacement was were $1 \mathrm{~mm} / \mathrm{min}$ in both tests.

The diameter of the core in the extrudate was inconstant through the extrusion direction, which means that the specimens E1, E2 and E3 had different interface diameters. In order to accomplish comparable push-out conditions, the diameter of the punch and die were exchangeable to fit the same relative location of the interface inside the die clearance. Configurations of both tests are shown in Table 2. The interface of AA7075/ 6060 bimetal specimens was not equidistantly positioned inside the die clearance to avoid the flow of the ductile AA6060 material into the die clearance. In this case, the stress state inside the die clearance would be shear instead of tension. The shear strength of the interface of AA7075/6060 can be calculated by.

$\tau_{i}=\frac{F_{\max }}{t \cdot \pi \cdot d_{i}}$

where $F_{\max }$ is the maximum shear force during the push-out test, $t$ is the thickness of the sample and $d_{i}$ is the diameter of the interface.

\section{Results and discussion}

\section{Interfacial zone}

Figure 6 shows the cross-sectional specimens that were extracted from the as-cast billet. The as-cast billets were designed to be rotationally symmetric. Nevertheless, the core and the sleeve were not perfectly round due to the imperfection of the casting condition. There was no visible gaps between core and sleeve at as-cast specimen $\mathrm{C} 1$, which was close to the casting gate (Fig. 6(a)). The bonding throughout the interface circle was non-symmetric on as-cast specimen C2 (Fig. 6(b)). The gap between core and sleeve was present almost along the whole interface on as-cast specimen $\mathrm{C} 3$ ((Fig. 6(c))). The push-out tests on $\mathrm{C} 3$ were not implemented, since the core and sleeve were easily separated during operations.

The diameter of the core, i.e. the thickness of the sleeve, is not homogeneously distributed along the extrudate's length in coextrusion. This is due to the complexity of material flow as well as the differences in velocity fields of core and sleeve materials. The core AA7075 material flowed into the die at first. At the same time, the friction between tool and sleeve as well as the dead metal zone slowed the flow of sleeve material close to the orifice. The diameter of the core is relatively lager in the tip and smaller in the end of the extrudate (Fig. 7). This effect cannot be avoid due to the different material flow properties. Secondly, the differences in the core diameter can be explained by an inhomogeneity of the shrinkage porosity over the height of the as-cast billet. Due to the solidification progress, the upper billet part shows an increased porosity especially within the substrate. When being eliminated during massive forming, those voids caused the differences in the core diameter.

\section{Microstructure}

During the compound casting phase, the heat input of the sleeve AA6060 alloy liquefies the fringe area of the substrate AA7075, while the sleeve AA6060 solidifies rapidly. The
Fig. 6 Interfaces of as-cast specimen: (a) specimen $\mathrm{C} 1$; (b) specimen $\mathrm{C} 2$; (c) specimen $\mathrm{C} 3$
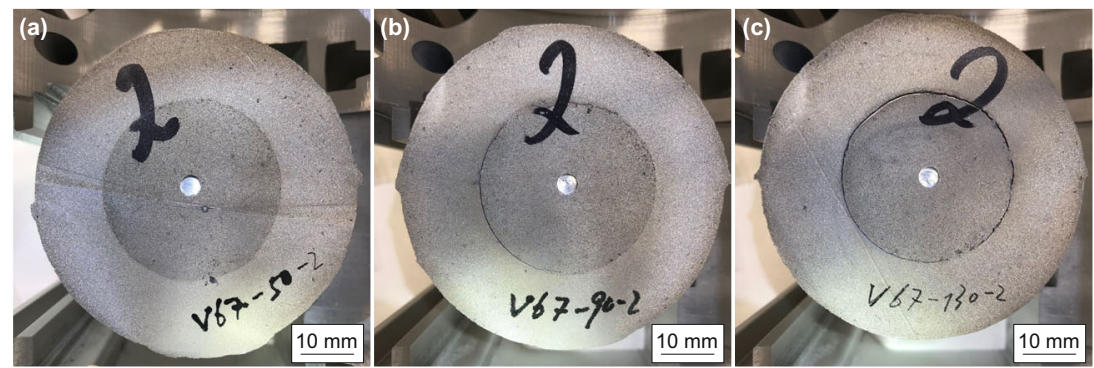


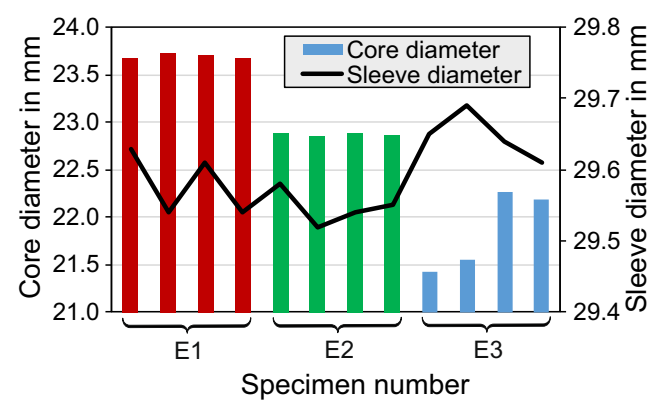

Fig. 7 Sleeve and core diameter of the extrudate along the extrusion direction

substrate AA7075 recrystallizes subsequently. The unequal coefficients of thermal expansion as well as the thermal conditions of the AA7075 and AA6060 induces non-uniform shrinkage of both layers during the cooling procedure, which cause crack initiation or dissolution of the dendrite network in the thixotropic state of AA7075. A large portion of pore can be seen inside of the substrate AA7075. Under the present thermal casting conditions, a large-scale cohesive bond can be achieved between the core and the sleeve. A sharp transition zone appears between the substrate and sleeve interface. This metallurgical bonding can be observed on the crosssection specimen $\mathrm{C} 1$ close to the casting gate. Nevertheless, the cohesive bond is non-symmetric throughout the complete circular interface in cross-sectional plain. The metallography captured from the same specimen at different positions show that voids and gaps between substrate and sleeve exist partially at the interface (Fig. 8).

Due to the non-uniform thermal condition through the casting direction (z-direction), weakly bonded interface areas were detected in greater distance from the casting gate (Fig. 9(b)). Partial bonding with local voids and gaps visibly presented along the interface circle of the cross-section. Almost no bonding can be achieved at a sample extraction distance of $130 \mathrm{~mm}$ from the casting gate (Fig. 9(c)). Inhomogeneously bonded interface areas are present in both cross-sectional plain and throughout the casting direction.

After hot extrusion, the bonding along bilayer interface circle of the cross-section is homogeneous, while the metallography on different positions of the cross-section sample presents similar. There are no visible pore or gaps between the core and sleeve layers throughout the entire circle of interface. The microstructure of sleeve AA6060 and core AA7075 is similar to the as-cast samples but with a refined grain size due to serve deformation. The AA6060 presents an angular structure of $\alpha$-Al. The AA7075 has a rounded $\alpha$-Al solid solution with Al-enriched inner structure and $\mathrm{Zn}$-rich outer area. The eutectic and intermetallic phases precipitate at the grain boundaries. Both core AA7075 and sleeve AA6060 show a relatively equiaxed grain structure in the nearinterface area in the cross-sectional samples of the extrudate (Fig. 10(a)). According to [18], the closure of the micro-voids can be enhanced by high temperature and high hydrostatic pressure. High temperature accelerates the diffusion of alloying atoms [19]. The extreme plastic deformation during the hot extrusion establishes the close contact between the substrate AA7075 and sleeve AA6060 by high normal contact stress between bilayers. A sound solid bonding was obtained under the hot extrusion condition. The uniformity of the bonding is not only present in the cross-sectional plain but also throughout the extrusion direction (Fig. 10). The metallography of the extrudate billet shows a uniformly bonded interface compared to the as-cast samples.

\section{Chemical analysis}

Figures 11 and 12 illustrate the phase composition and diffusion of the near-interface area of the as-cast and extrudate sample respectively by SEM-EDS. The voids and gaps in as-cast specimens presented low level of Al mass. The micro-voids also caused the large deviation of the measured composite fractions. The high amount of $\mathrm{Si}$ attributed to the grinding and polishing procedure in the SEM specimen preparation. The analysis in Fig. 11(a) shows a relatively large transition zone between core AA7075 and sleeve AA6060 interface at as-cast specimen $\mathrm{C} 1$, which indicates a high diffusion between the joining partners during the compound casting process close to the casting gate.

Compared to the as-cast specimens, there were less microvoids in the interface and core AA7075 of extrudate specimen
Fig. 8 Metallography captured at different position of the crosssectional sample $\mathrm{C} 1$ : (a) partially bonded interface with gaps; (b) good cohesive bonding

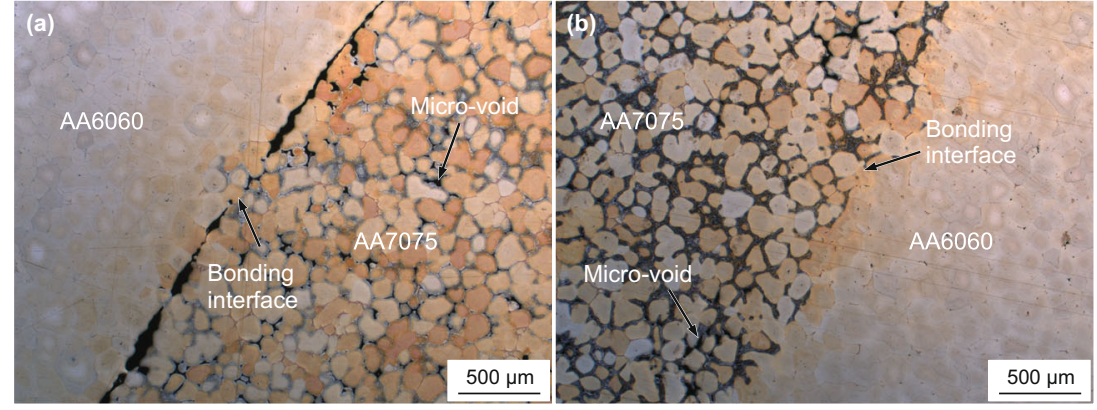


Fig. 9 Metallography of the cross-section samples at different z-positions of the as-cast billet: (a) specimen $\mathrm{C} 1$; (b) specimen $\mathrm{C} 2$;

(c) specimen $\mathrm{C} 3$
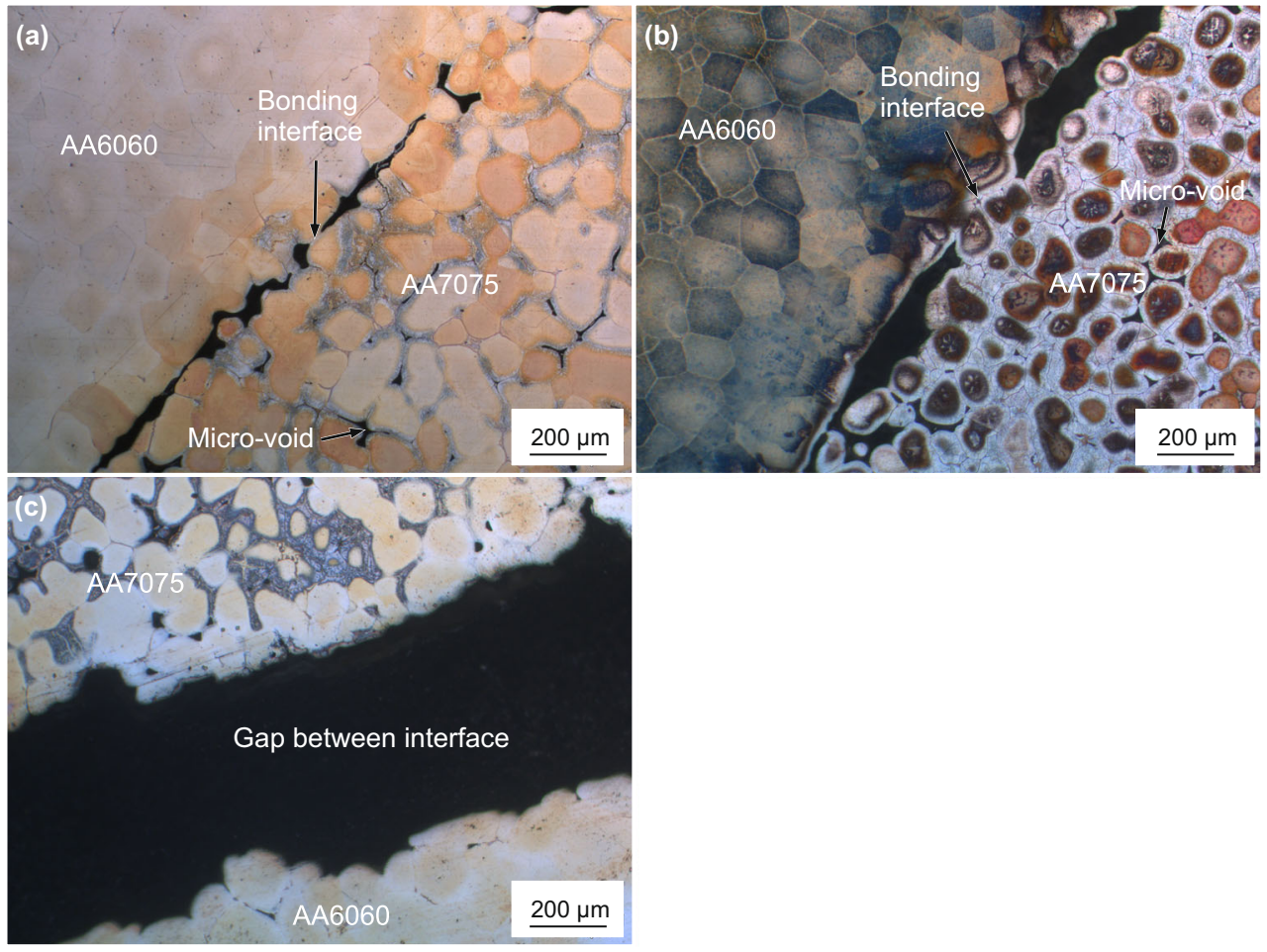

(Fig. 12). The compositional analysis yields that the transition zone was approximately $0.2 \mathrm{~mm}$, which was almost constant in the extrudate specimens E1, E2 and E3. The homogenization of the bonding was validated by the EDS analysis.

\section{Microhardness}

The microhardness of as-cast and extrudate bilayer specimens is shown in Fig. 13. The hardness of the core
Fig. 10 Metallography of the cross-section samples at the different z-positions of the extruded billet: (a) specimen E1; (b) specimen E2; (c) specimen E3
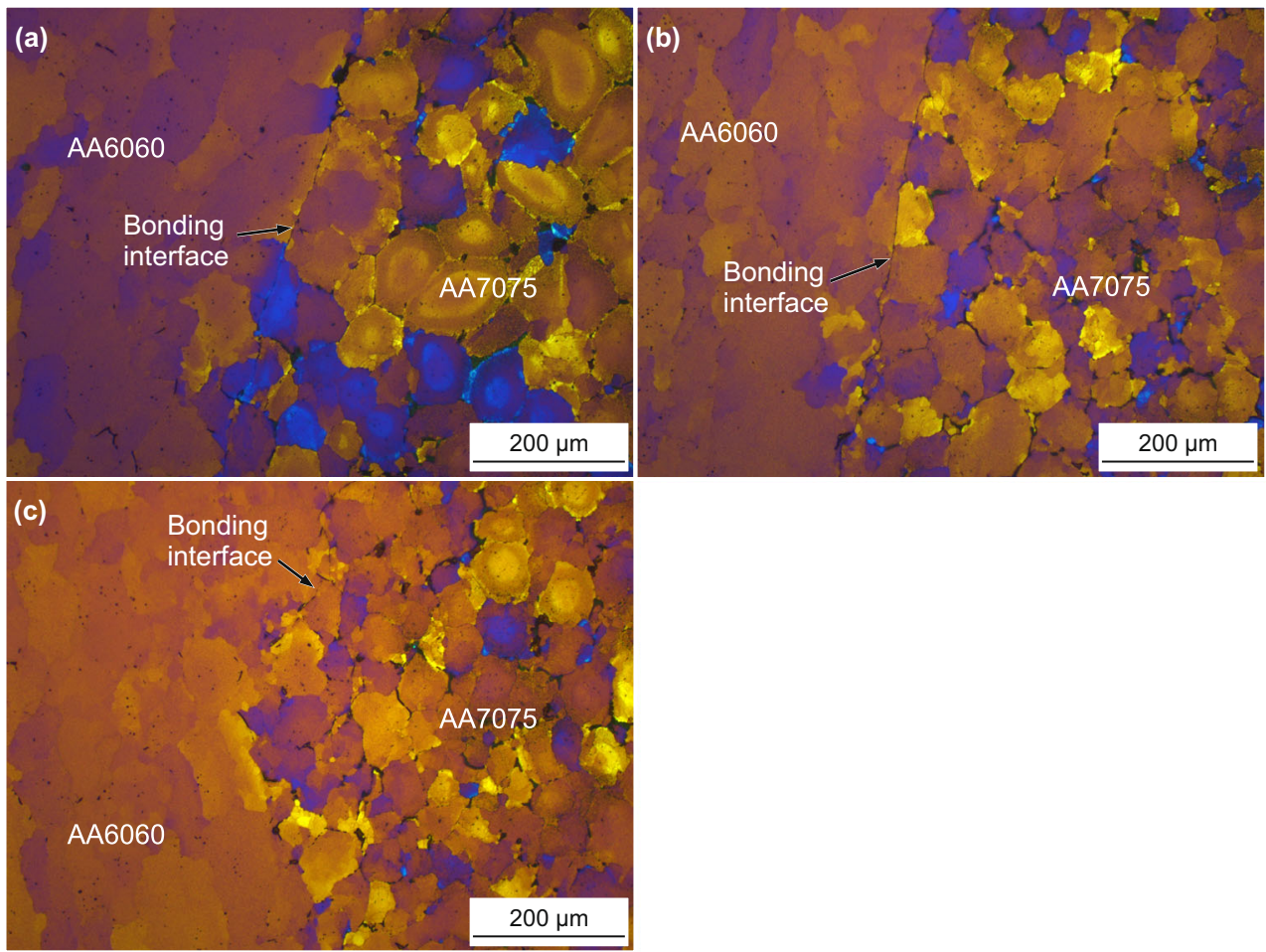

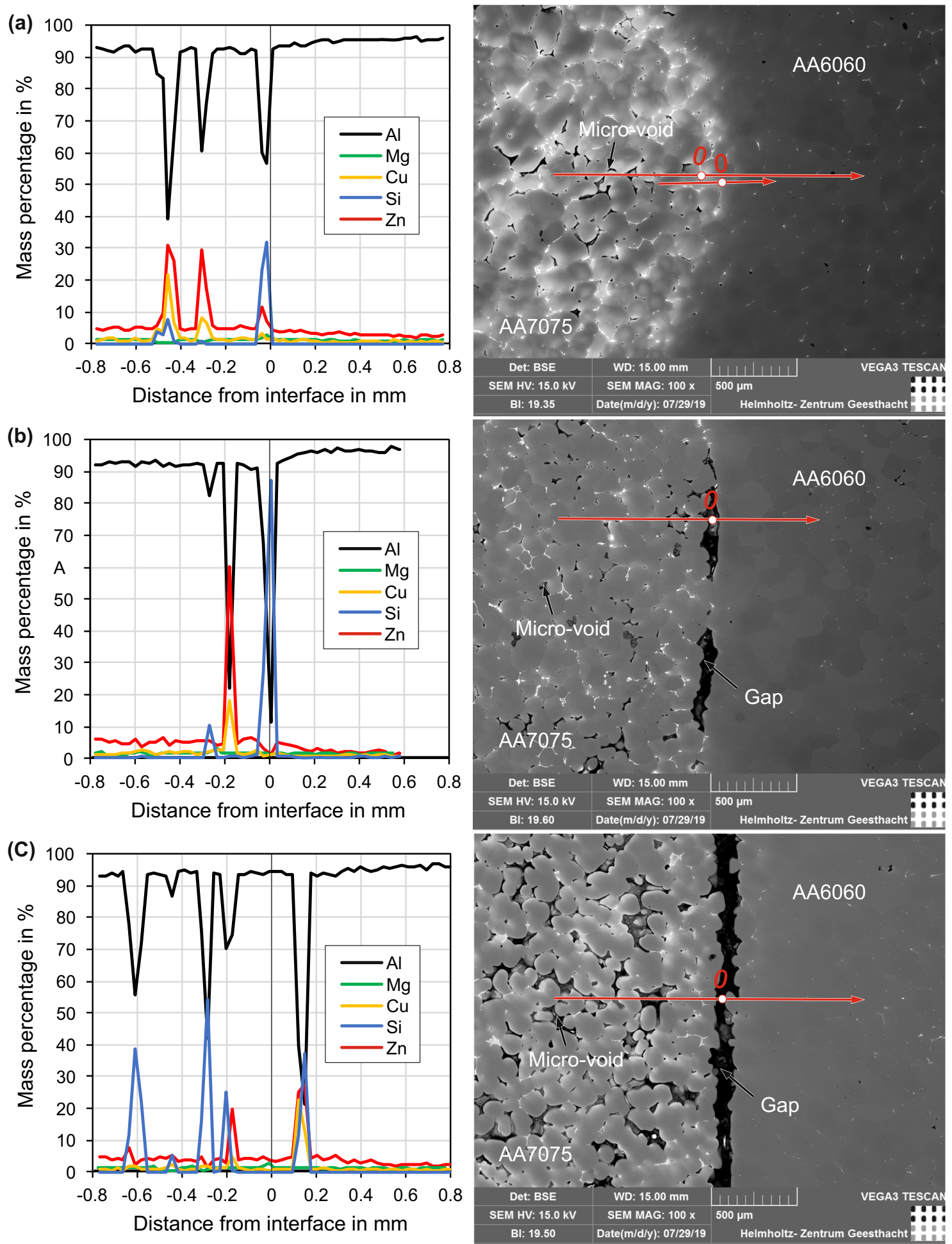

Fig. 11 SEM-EDS analysis of the near-interface region of as-cast specimens: (a) C1; (b) C2; (c) C3

AA7075 and sleeve AA6060 is similar to the characteristic monolithic hardness. It has to be mentioned that the gap between core and sleeve in $\mathrm{C} 3$ shown in Fig. 9(c) is larger than $0.5 \mathrm{~mm}$. The microhardness close to the interface would be inaccurate due to the lack testing area. The severe scattering of the microhardness in the core AA7075 is due to the pores and intermetallic phases at grain boundaries inside the core. Indentation close or on the pore induces lower microhardness. The bonding quality at different $\mathrm{z}$ positions of the as-cast billet did not significantly influence 

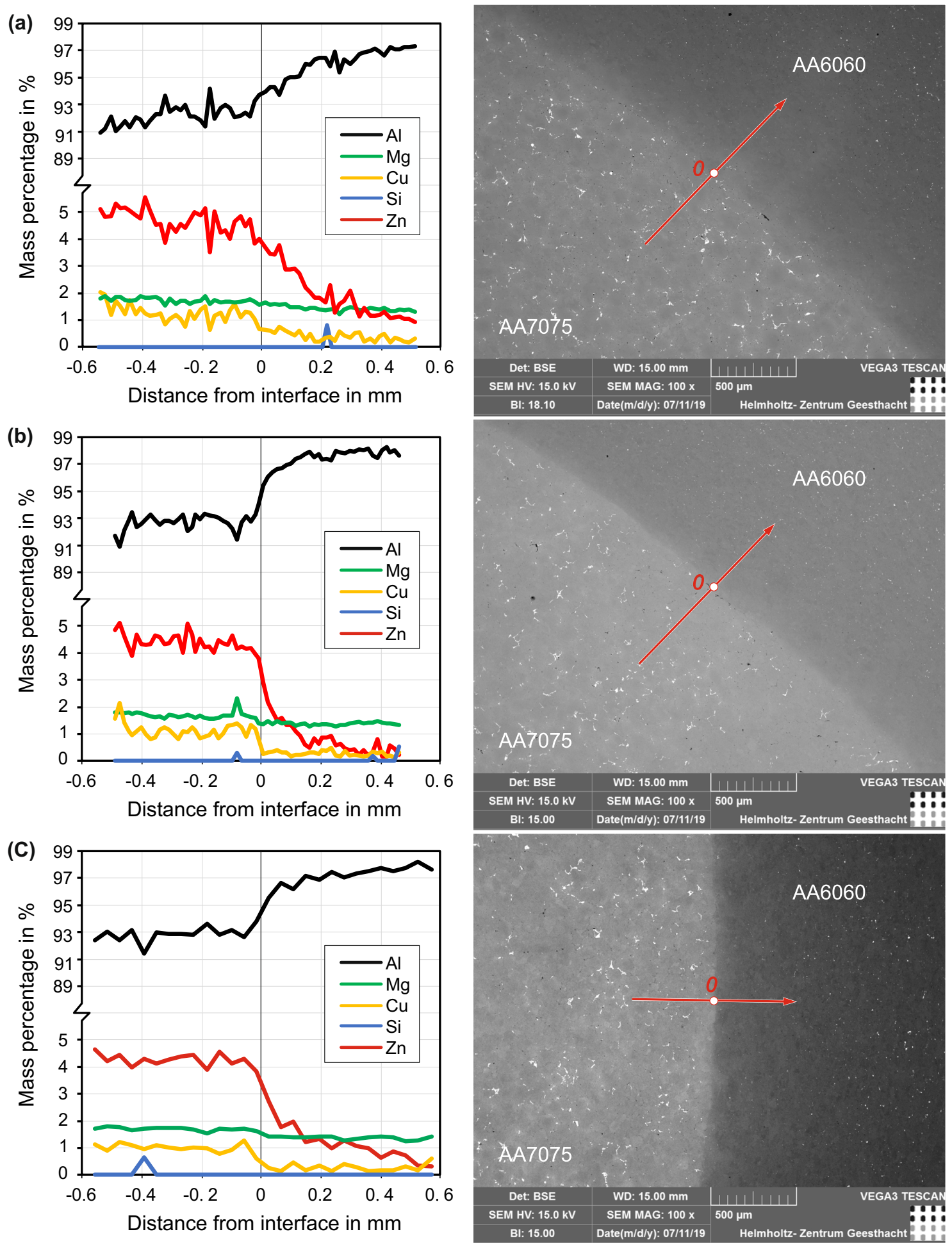

Fig. 12 SEM-EDS analysis of the near-interface region of extrudate specimens: (a) E1; (b) E2; (c) E3. 15

the hardness of the bimetal. The hardness after hot extrusion presents a similar level as the as-cast billet. Nevertheless, uniform microhardness values are measured inside the core and sleeve material, as the defects in the casting, e.g. pores, are eliminated by hot extrusion. A sharp transition zone at the geometrical interface is determined using the hardness testing method. The transition zone is similar on both the as-cast and extrudate samples. 


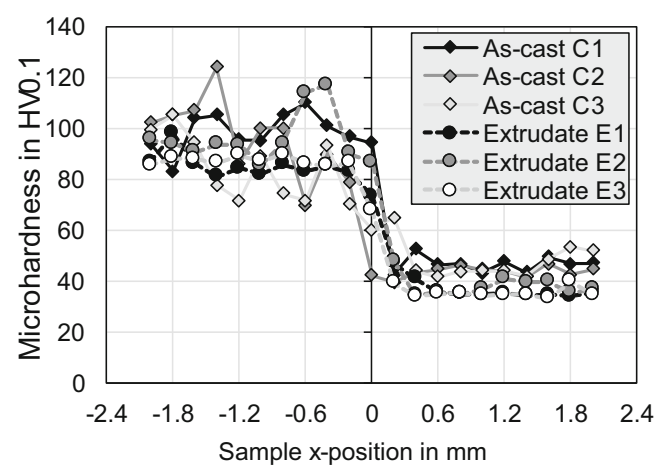

Fig. 13 Microhardness of as-cast and extrudate AA7075/6060 bimetals

\section{Shear strength}

According to [16], the failure of as-cast samples $\mathrm{C} 1$ during push-out testing appears in the core material instead of the interface. The metallic bonding of the specimen $\mathrm{C} 1$ is described as a smooth transition based on a graded aluminum matrix. Visible pores appear in the core AA7075 of the as-cast billets due to the unequal thermal expansion of the core and shell materials. This defect induces the relatively low strength of the core material compared to conventional wrought AA7075 material. In as-cast sample, the mechanical strength of the core AA7075 is weaker than expected. Therefore, hybrid sample failure is initiated inside the AA7075 core material. The shear strength of the as-cast samples is influenced by the strength of the core AA7075 material. The as-cast specimen $\mathrm{C} 3$ cannot be analyzed by push-out testing, because the core and sleeve already separated during the specimen preparation. The shear strength of AA7075 and AA6060 were obtained from the push-out test of monolith AA7075 and AA6060 cast billets. Details about the push-out test on as-cast specimens were present in [17].

Figure 14 shows an example of force-displacement curve of the push-out test on specimen E1 and the shear strengths of the as-cast and extrudate specimens together. As it was depicted previously, the mechanical properties of the core AA7075 were improved by hot extrusion. Therefore, the shear strength of the interface of extrudate E1 specimen was in- creased comparing the as-cast $\mathrm{C} 1$. The significant improvement of interfacial bonding by co-extrusion was the homogenization of the bonding strength throughout the extrusion direction. The shear bonding strength of the extrudate specimens were higher than the monolith AA6060 material, which indicated a metallurgical bonding was generated throughout the whole extruded billets.

\section{Conclusions}

The evolution of the interfacial bonding of AA7075/6060 bilayer billets throughout the process chain of discontinuous compound casting and hot extrusion was investigated. The metallography, chemical composition analysis as well as mechanical tests were conducted to depict the evolution of the bonding properties. The conclusion was drawn as follows:

- Metallurgical bonding can be achieved by using appropriate casting conditions. Remelting and recrystallization are important mechanisms to form a cohesion with solid solutions at the interface. A small diffusion zone and a shear bonding strength up to $93.8 \mathrm{MPa}$ are reached.

- Due to the non-uniform thermal conditions during static compound casting inhomogeneous bonding along the casting direction and non-symmetrical bonding in crosssectional plain present in discontinuous compound casting process.

- The hot extrusion process significantly homogenizes the interfacial bonding in the above-mentioned aspects. The high pressure and temperature improve the mechanical properties of the core AA7075 material, as the voids during discontinuous compound casting process are eliminated. The shear bonding strength increases from maximum of 93.8 $\mathrm{MPa}$ to $145.9 \mathrm{MPa}$, which is close to the monolithic AA7075 material.

The future work is planned concerning the influence of extrusion parameters, e.g. temperature, extrusion ratio on the evolution of the interface bonding.
Fig. 14 Push-out test results: (a) force-displacement curve of extrudate specimen E1; (b) shear strength of the as-cast and extrudate specimens (a)

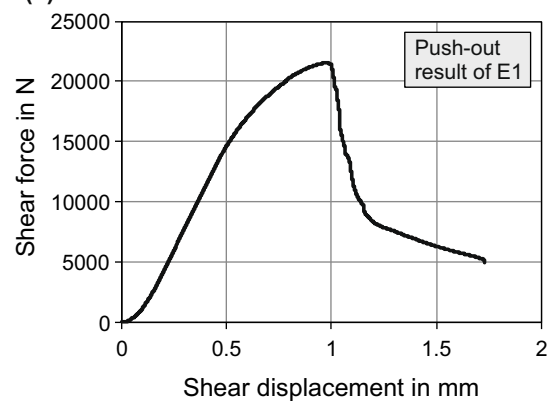

(b)

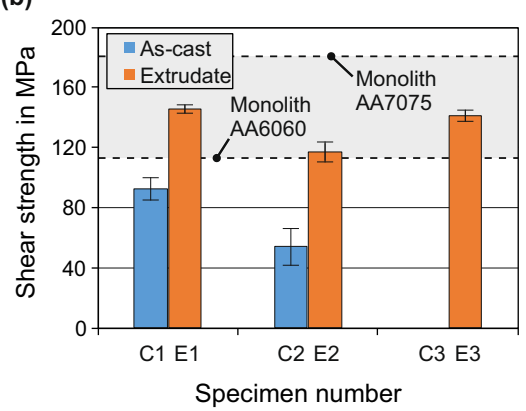


Acknowledgements The authors acknowledge the financial funding from DFG and would like to thank Petra Fischer for her support.

Funding Open Access funding enabled and organized by Projekt DEAL. This study was funded by the German Research Foundation (DFG) [grant number BE5196/11 - 1].

Data availability The raw/processed data required to reproduce these findings cannot be shared at this time as the data also forms part of an ongoing study.

\section{Declarations}

Conflict of interest The authors declare that they have no conflict of interest.

Open Access This article is licensed under a Creative Commons Attribution 4.0 International License, which permits use, sharing, adaptation, distribution and reproduction in any medium or format, as long as you give appropriate credit to the original author(s) and the source, provide a link to the Creative Commons licence, and indicate if changes were made. The images or other third party material in this article are included in the article's Creative Commons licence, unless indicated otherwise in a credit line to the material. If material is not included in the article's Creative Commons licence and your intended use is not permitted by statutory regulation or exceeds the permitted use, you will need to obtain permission directly from the copyright holder. To view a copy of this licence, visit http://creativecommons.org/licenses/by/4.0/.

\section{References}

1. Ben Khalifa N, Foydl A, Pietzka D, Jäger A, Tekkaya AE (2014) Extrusion of multi-material components. In: International Manufacturing Science and Engineering Conference, vol 45813. American Society of Mechanical Engineers, New York, $p$ V002T02A088

2. Müller K Strangpressen von Halbzeugen aus metallischen Verbundwerkstoffen (2001) In: Strangpressen. Bauser M, Sauer G, Siegert K (Hrsg), 2. Auflage, Aluminium-Verlag, Düsseldorf, pp 464-483

3. Wagener HW, Haats J (1994) Pressure welding of corrosion resistant metals by cold extrusion. J Mater Process Technol 45(1-4): 275-280

4. Gumm P, Hofmann W (1964) Kombination von Umformung und Kaltpressschweissen beim Fliesspressen und Rohrziehen. VDIVerlag, Düsseldorf

5. Ciupik LF (1984) Mechanisms of cold deformation bonding of metals during their simultanious plastic flow. Adv Technol Plast $1: 133$
6. Ruge J, Böhme K (1972) Stand der Entwicklung und Anwendung des Kaltpreßschweißens. Mater Werkst 3(6):286-291

7. Riemelmoser F, Kilian H, Widlicki P, Thedja WW, Müller K, Garbacz H, Kurzydlowski KJ (2007) Co-extrusion von aluminium magnesium verbundwerkstoffen. In: Strangpressen: Tagungsband des Symposiums Strangpressen des Fachausschusses Strangpressen der DGM. Wiley-VCH Verlag GmbH \& Co. KGaA, Weinheim, p 248-257

8. Grittner N, Striewe B, von Hehl A, Bormann D, Hunkel M, Zoch HW, Bach FW (2012) Co-extrusion of aluminium-titanium-compounds. In: Key Engineering Materials, vol 491. Trans Tech Publications, Schwyz, pp 67-74

9. Dietrich D, Grittner N, Mehner T, Nickel D, Schaper M, Maier HJ, Lampke T (2014) Microstructural evolution in the bonding zones of co-extruded aluminium/titanium. J Mater Sci 49(6):2442-2455

10. Ißleib A, Friedel A, Lubojanski I (1995) Verbundgießen von EisenKohlenstoff-Legierungen-grundlegende metallurgische Reaktionen an der Grenzfläche-Teil I. Gießerei-Praxis 15(16): 286-289

11. Papis KJM, Hallstedt B, Löffler JF, Uggowitzer PJ (2008) Interface formation in aluminium-aluminium compound casting. Acta Mater 56(13):3036-3043

12. Ißleib A, Friedel A, Lubojanski I (1995) Verbundgießen für Verschleißteile - Stand und Zukunftsaussichten. Gießerei-Praxis 7(8):146-150

13. Lange A (1999) Verbundgießen für Anwendungen in der Verschleißtechnik, Dissertation, Otto-von-Guericke-Universität Magdeburg

14. Pelz C (2000) Verbundgußverfahren zur Herstellung belastungsangepaßter Werkzeuge am Beispiel des Gesenkschmiedens. VDI Verlag, Düsseldorf

15. Anderson MD, Kubo KT, Bischoff TF, Fenton WJ, Reeves EW, Spendlove B, Bruce R (2005) Method for Casting Composite Ingot, US Patent US 2005/0011630 A1

16. Greß T, Mittler T, Schmid S, Chen H, Khalifa NB, Volk W (2018) Thermal analysis and production of as-cast Al 7075/6060 bilayer billets. Int J Metalcast 13:1-13

17. Greß T, Stahl J, Mittler T, Spano L, Chen H, Khalifa NB, Volk W (2019) Mechanical characterization of as-cast AA7075/6060 and CuSn6/Cu99. 5 compounds using an experimental and numerical push-out test. Mater Sci Eng A 751:214-225

18. Yu J, Zhao G, Cui W, Zhang C, Chen L (2017) Microstructural evolution and mechanical properties of welding seams in aluminum alloy profiles extruded by a porthole die under different billet heating temperatures and extrusion speeds. J Mater Process Technol 247:214-222

19. Tang J, Chen L, Fan X, Zhao G, Zhang C (2018) Co-extrusion of dissimilar AA6063/AA7075 by porthole die at various temperatures. J Alloy Compd 764:162-169

Publisher's Note Springer Nature remains neutral with regard to jurisdictional claims in published maps and institutional affiliations. 